\title{
Hydrothermal synthesis method of nickel phosphide nanoparticles
}

\author{
Bo Wang $\cdot$ Xiang Huang $\cdot$ Zhibin Zhu $\cdot$ \\ He Huang $\cdot$ Jinhui Dai
}

Received: 13 December 2011/ Accepted: 1 January 2012/Published online: 14 January 2012

(C) The Author(s) 2012. This article is published with open access at Springerlink.com

\begin{abstract}
Nanometer nickel phosphide compounds $\left(\mathrm{Ni}_{2} \mathrm{P}\right.$ and $\mathrm{Ni}_{12} \mathrm{P}_{5}$ ) were synthesized via a mild hydrothermal method with red phosphor and nickel chloride as raw materials. XRD, EDS, TEM and SEM analysis were employed to characterize the obtained products. The results showed that the as-prepared products were well crystallized and particle sizes ranged from 10 to $40 \mathrm{~nm}$. Effects of raw material ratios and initial $\mathrm{pH}$ of reaction system on the final products were investigated. The result showed that increased $\mathrm{P} / \mathrm{Ni}$ ratio benefited the formation of $\mathrm{Ni}_{2} \mathrm{P}$ but went against obtaining $\mathrm{Ni}_{12} \mathrm{P}_{5}$ and nanoparticles were obtained only in alkaline environment.
\end{abstract}

Keywords Nanocrystalline materials · Nickel phosphides . Hydrothermal $\cdot$ Red phosphor

\section{Introduction}

Owning to the great application prospects as catalytic agent (Oyama 2003; Muettcrties and Sauer 1974), synthesis of nickel phosphide compounds has been of great interest to researchers. There have been many methods such as chemical combination by elementary substances directly (Rundqvist 1966), replacement reaction by solidity (Fjellvag et al. 1984) chemical reaction between metal halide lamp and phosphate (Rowley and Parkin 1993) decomposition of organic compound of metal (Gingerich 1964), electrolysis of molten salt (Li et al. 1998), and deoxidization of phosphate, etc. (Gopalakrishnan et al. 1997) to produce them. But none

B. Wang $\cdot$ X. Huang $(\bowtie) \cdot$ Z. Zhu $\cdot$ H. Huang $\cdot$ J. Dai Institute of Materials Science and Engineering, Ocean University of China, No. 238 Songling Road, Qingdao 266100, China e-mail: huangxianghd@gmail.com of the above methods is with the advantages of being clean, low energy consumption and easy-to-approach conditions.

Stephanie L. Brock and her co-workers have firstly reported solvothermal syntheses of $\mathrm{Cu}_{3} \mathrm{P}$ (Aitken et al. 2005). Thereafter, our group has synthesized micrometer phosphides and nanometer $\mathrm{Co}_{2} \mathrm{P}$ with hydrothermal method using red phosphorus as raw material (Liu et al. 2010; Huang et al. 2010, 2011). Until now, few related studies have paid any attention to the above-mentioned synthesis process. In the present work, synthesis of nanometer $\mathrm{Ni}_{2} \mathrm{P}$ and $\mathrm{Ni}_{12} \mathrm{P}_{5}$ by hydrothermal process has been presented. The hydrothermal experiments were conducted under a relative low temperature $\left(200^{\circ} \mathrm{C}\right)$ for only $10 \mathrm{~h}$ with red phosphor as raw material. Important parameters like ratio of raw material and $\mathrm{pH}$ of reaction system have been considered to study their effect on powder characteristics such as phase, morphology and particle size. According to the experimental results, a hydrothermal method to synthesize nanometer nickel phosphide compounds $\left(\mathrm{Ni}_{2} \mathrm{P}\right.$ and $\left.\mathrm{Ni}_{12} \mathrm{P}_{5}\right)$ has been summarized in this paper.

\section{Experiments}

Preparation of the reacting suspension and samples

Starting materials used in the experiments were analytical reagents. All the reagents were purchased from Sinopharm Chemical Reagent Co., Ltd and used as received. The red phosphor $(\mathrm{P})$ and $\mathrm{NiCl}_{2} \cdot 6 \mathrm{H}_{2} \mathrm{O}(\geq 99.0 \%)$ were used as phosphor and nickel sources. $\mathrm{KOH}(\geq 82.0 \%)$ was used to establish an alkali reacting environment. The reacting suspension was prepared as follows: first, red phosphor was ground in a mortar to get well-distributed small powders. 
Table 1 Hydrothermal experiment conditions in the present work

\begin{tabular}{llllllll}
\hline $\begin{array}{l}\text { Group } \\
\text { Patio) }\end{array}$ & $\begin{array}{l}\text { Peaction time } \\
\text { (h) }\end{array}$ & $\begin{array}{l}\text { Starting Ni } \\
(\mathrm{mol} / \mathrm{L})\end{array}$ & $\begin{array}{l}\text { Starting } \\
(\mathrm{mol} / \mathrm{L})\end{array}$ & $\begin{array}{l}\text { Temperature } \\
\left({ }^{\circ} \mathrm{C}\right)\end{array}$ & \begin{tabular}{l}
$\mathrm{pH}$ value \\
\cline { 5 - 7 }
\end{tabular} \\
\hline $\mathrm{A}$ & $15 / 1$ & 10 & 0.052 & 0 & 200 & 6.0 & 1.5 \\
$\mathrm{~B}$ & $20 / 1$ & 10 & 0.038 & 0 & 200 & 6.0 & 1.5 \\
$\mathrm{C}$ & $25 / 1$ & 10 & 0.031 & 0 & 200 & 6.0 & 1.5 \\
$\mathrm{D}$ & $30 / 1$ & 10 & 0.026 & 0 & 200 & 6.0 & 1.5 \\
$\mathrm{E}$ & $15 / 1$ & 10 & 0.052 & 1 & 200 & 13.0 & 3.0 \\
$\mathrm{~F}$ & $20 / 1$ & 10 & 0.038 & 1 & 200 & 13.0 & 3.0 \\
$\mathrm{G}$ & $25 / 1$ & 10 & 0.031 & 1 & 200 & 13.0 & 3.0 \\
$\mathrm{H}$ & $30 / 1$ & 10 & 0.026 & 1 & 200 & 13.0 & 3.0 \\
\hline
\end{tabular}
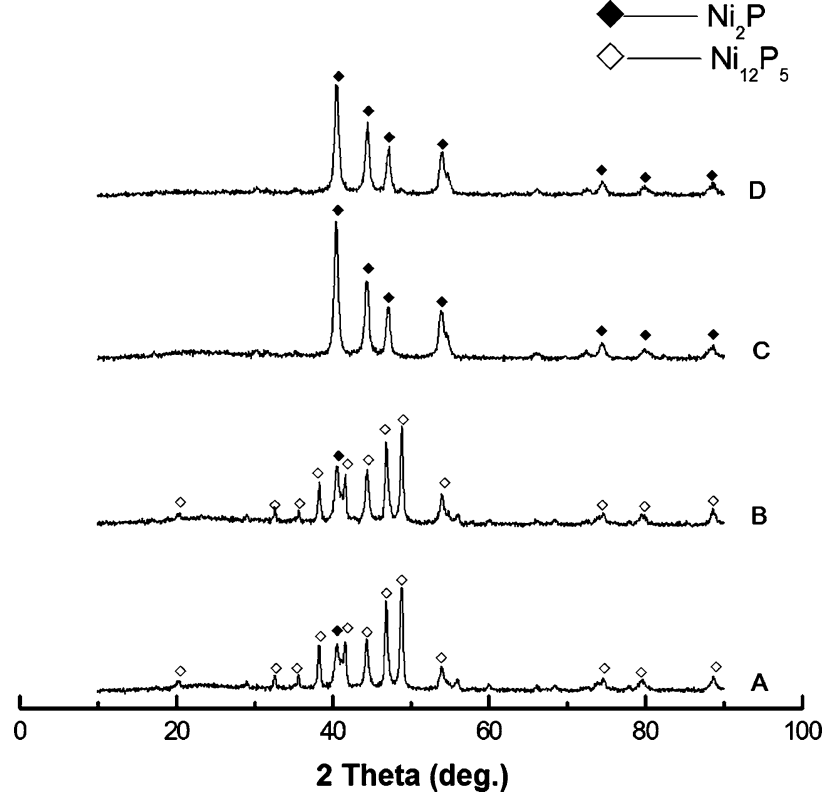

Fig. 1 X-ray powder diffraction patterns of the samples (Groups $A-D$ )

Then a desired amount of $\mathrm{NiCl}_{2} \cdot 6 \mathrm{H}_{2} \mathrm{O}$ and the as-ground red phosphor were added to $64 \mathrm{ml}$ distilled water under vigorous stirring to get mixed aqueous suspension (Table 1). $\mathrm{KOH}$ as a variable factor of the process was only used in Groups E, F, $\mathrm{G}$ and $\mathrm{H}$.

The prepared suspension was poured into a Teflon-lined autoclave with 0.8 filling factor, sealed, and hydrothermally treated at $200^{\circ} \mathrm{C}$ for $10 \mathrm{~h}$. After the autoclave cooled to room temperature, the black products were collected and washed with plenty of distilled water. They were then dried at $50^{\circ} \mathrm{C}$ for $5 \mathrm{~h}$ in the air.

\section{Characterization}

Phase constitution, chemical composition and morphology of the samples were characterized by X-ray powder

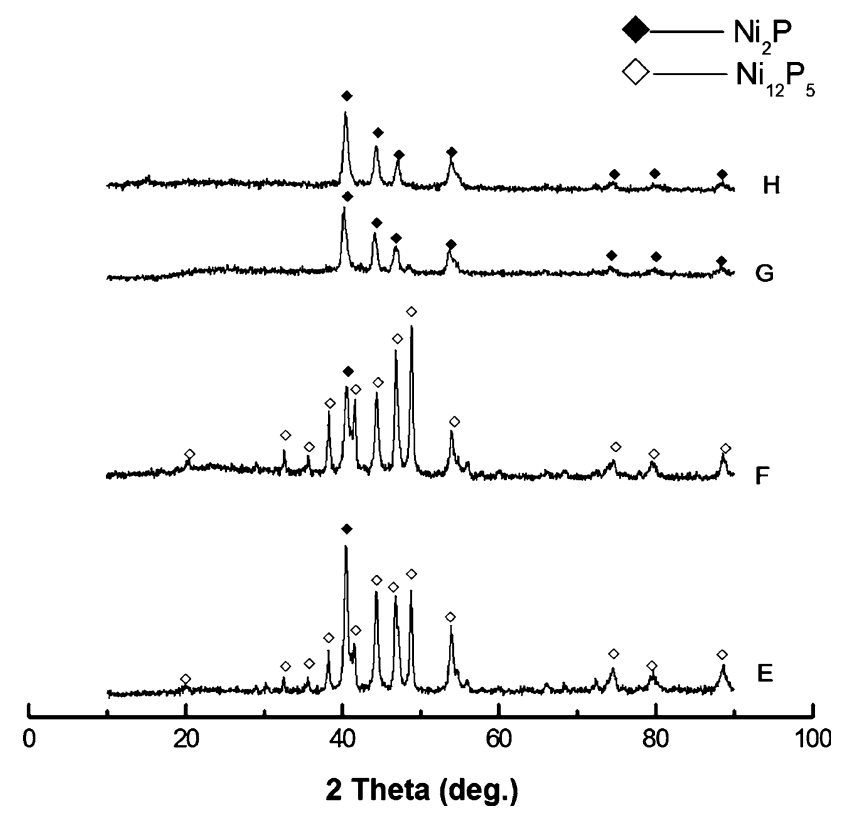

Fig. 2 X-ray powder diffraction patterns of the samples (Groups $E-H$ )

diffraction (XRD, Model D/max Rigaku Co., Japan) with $\mathrm{Cu}$ $\mathrm{K}_{\alpha}$ radiation $(40 \mathrm{kV}, 150 \mathrm{~mA})$, energy dispersive $\mathrm{X}$-ray spectroscopy (Oxford Instruments' INCA EDS system), scanning electron microscopy (SEM, Model JSM-840, JEOL Co., Japan), and transmission electron microscopy (TEM, Model JEM-1200EX, JEOL Co., Japan), respectively.

\section{Results and discussions}

The X-Ray diffraction patterns of as-prepared products are presented in Figs. 1 and 2. The sharp peaks indicated that all the samples were well crystallized. Diffraction peaks of Groups A and B could be readily indexed to $\mathrm{Ni}_{12} \mathrm{P}_{5}$ with a small amount of $\mathrm{Ni}_{2} \mathrm{P}$. When the starting molar ratios of 
P/Ni were 25:1 and 30:1 (Groups C and D), respectively, the reflection peaks had a good agreement with the crystalline phase of $\mathrm{Ni}_{2} \mathrm{P}$ without any impurity.

Groups $\mathrm{E}$ and $\mathrm{F}$ had almost the identical XRD patterns with Group A and Group B, which had a good agreement with the crystalline phase of $\mathrm{Ni}_{12} \mathrm{P}_{5}$. The products of Groups $\mathrm{C}, \mathrm{D}, \mathrm{G}$, and $\mathrm{H}$ were all $\mathrm{Ni}_{2} \mathrm{P}$. The XRD results were corroborated by the EDS test. The EDS spectra of Groups $\mathrm{A}$ and $\mathrm{G}$ in Fig. 3 show the presence of Ni and $\mathrm{P}$ in the final products, and no impurity peaks were found. The $\mathrm{Ni} / \mathrm{P}$ ratios in Fig. 3 were 2.29:1 and 2.09:1, respectively.

But enormous differences in size were observed through their SEM and TEM images (Fig. 4). The obtained products with $\mathrm{KOH}$ (Groups $\mathrm{E}-\mathrm{H}$ ) had a relatively homogeneous size

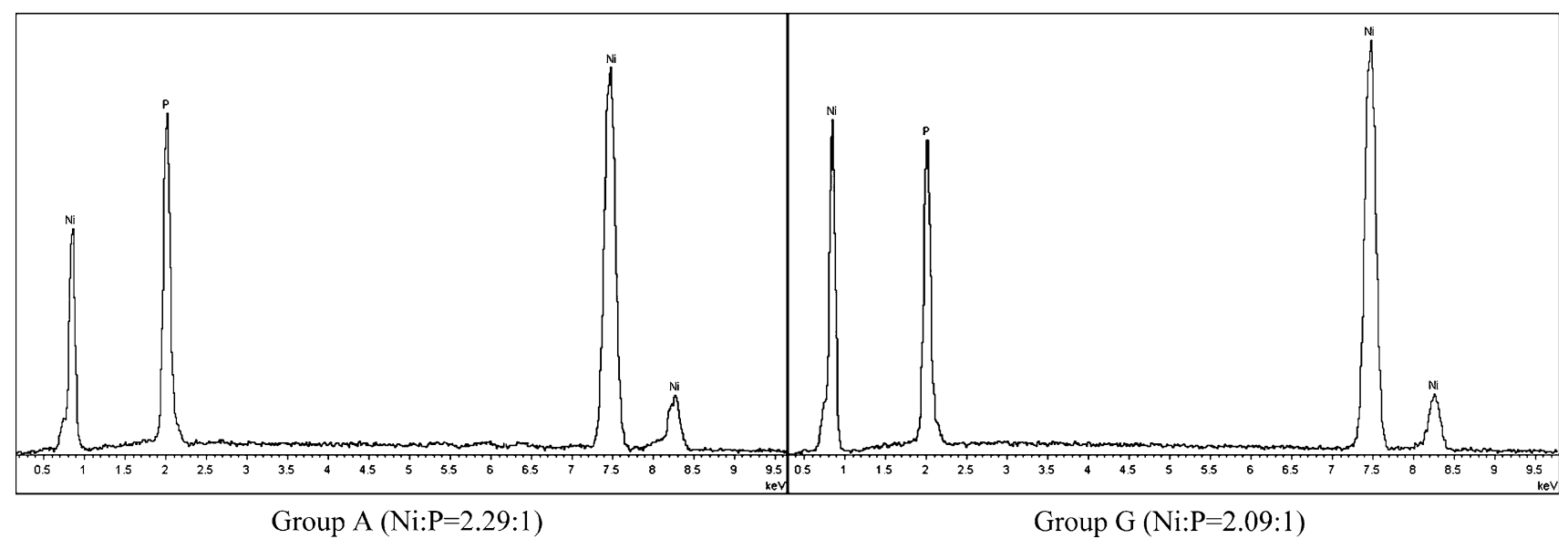

Fig. 3 EDS spectra of as-prepared samples (Groups $A$ and $G$ )
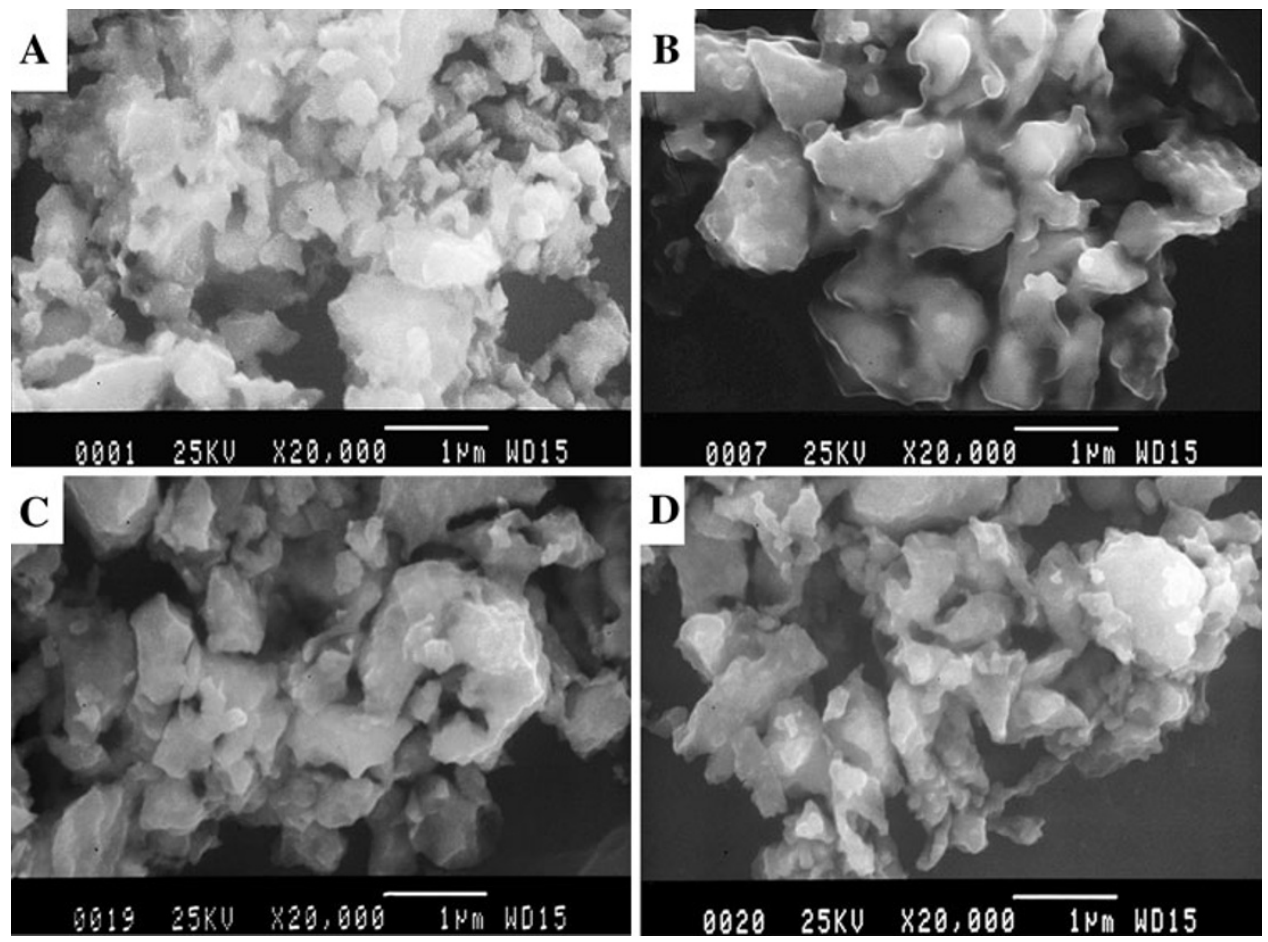

Fig. 4 SEM $(A-D)$ and TEM $(E-H)$ images of the as-prepared samples 


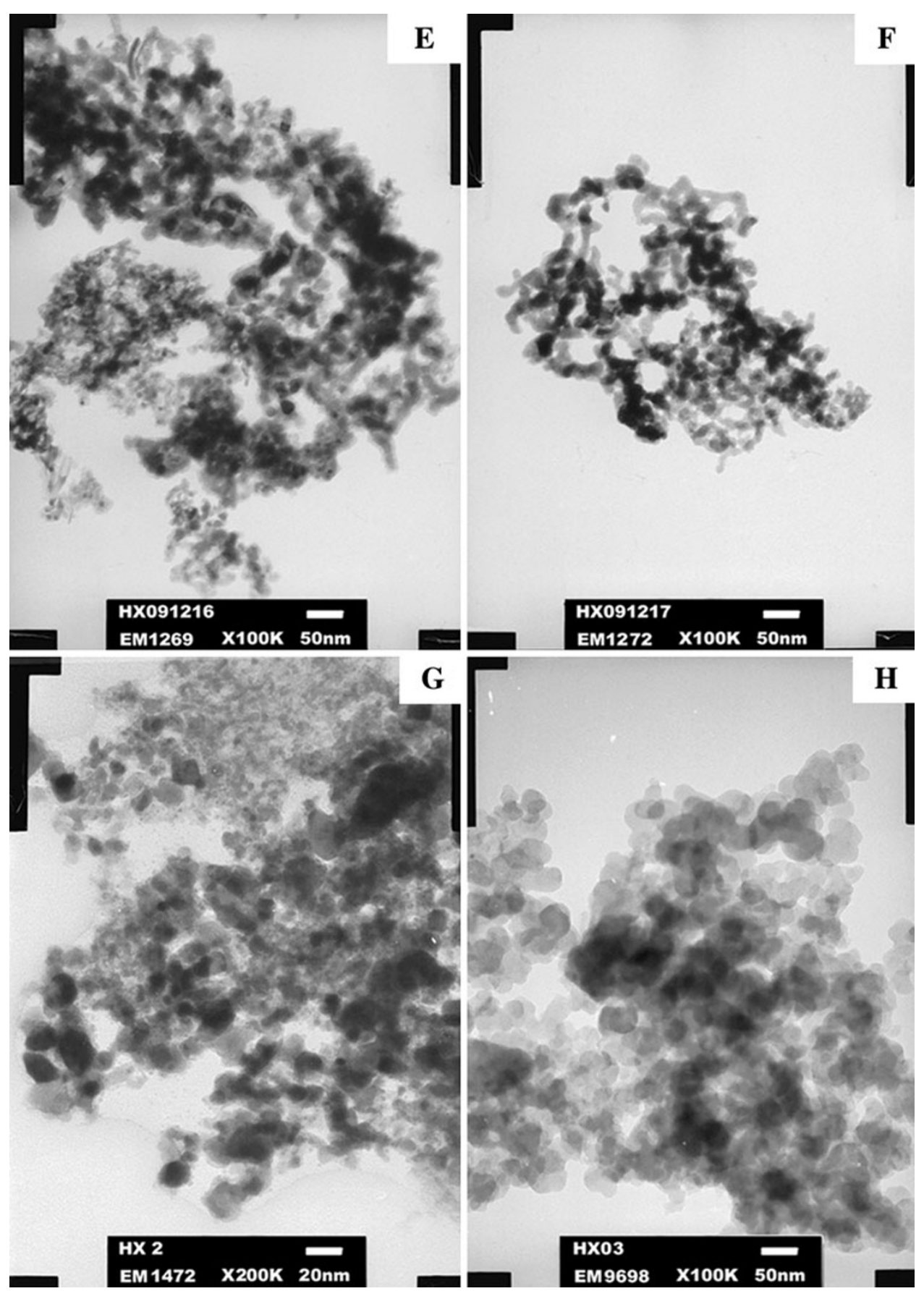

Fig. 4 continued

with an average particle size of about $30 \mathrm{~nm}$, while the sizes of samples synthesized without $\mathrm{KOH}$ (Groups A-D) varied from 1 to $100 \mu \mathrm{m}$.

The crystal sizes of Groups E, F, G and H were calculated with Scherrer equation (Patterson 1939): $D_{\mathrm{c}}=0.89 \lambda /(B \cdot \cos \theta)$, where $D_{\mathrm{c}}$ is the diameter of the particles; $\lambda=1.518 \AA$ (Cu Ka radiation wavelength); $B$ is the full width at half maxima and $\theta$ is the
Bragg's angle. By substituting these values, the size of the nanoparticles was found to be about $10-40 \mathrm{~nm}$, which were in close agreement with TEM results. Images of the samples in Fig. 4 also show that none of the as-prepared powders had uniform and regular shape.

The probable reaction process for the formation of $\mathrm{Ni}_{2} \mathrm{P} /$ $\mathrm{Ni}_{12} \mathrm{P}_{5}$ could be summarized as follows (Wang et al. 2008). 


$$
\begin{aligned}
& \mathrm{P}+7 \mathrm{OH}^{-} \rightarrow \mathrm{HPO}_{4}^{2-}+3 \mathrm{H}_{2} \mathrm{O}+5 \mathrm{e} \\
& \mathrm{Ni}^{2+}+2 \mathrm{e} \rightarrow \mathrm{Ni} \\
& 2 \mathrm{Ni}+\mathrm{P} \rightarrow \mathrm{Ni}_{2} \mathrm{P} \\
& 12 \mathrm{Ni}+5 \mathrm{P} \rightarrow \mathrm{Ni}_{12} \mathrm{P}_{5}
\end{aligned}
$$

Obviously, $\mathrm{KOH}$ in the present study could provide $\mathrm{OH}^{-}$for Eq. 1 and facilitate phosphor to dissolve in water. Companied with the dissolution of phosphor, smaller and relatively homogeneous red phosphor particles were obtained in the suspension. As a result, the reaction between red phosphor and nickel chloride tended to get smaller products. The effect of $\mathrm{KOH}$ on the particle size could be observed easily in Fig. 4.

\section{Conclusions}

In summary, nanometer nickel phosphide compounds $\left(\mathrm{Ni}_{2} \mathrm{P}\right.$ and $\left.\mathrm{Ni}_{12} \mathrm{P}_{5}\right)$ were successfully synthesized in a mild hydrothermal process based on the reactions of red phosphor and nickel chloride. Molar ratio of raw materials was the critical factor for the type of final products, and the alkaline environment was necessary to get nanoparticles in the present work.

Acknowledgments Financial support from Ocean University of China through Young Teachers' Scientific Research Special Fund Projects (No. 201113038) is gratefully acknowledged.

Open Access This article is distributed under the terms of the Creative Commons Attribution License which permits any use, distribution and reproduction in any medium, provided the original author(s) and source are credited.

\section{References}

Aitken JA, Ganzha-Hazen V, Brock SL (2005) Solvothermal syntheses of $\mathrm{Cu}_{3} \mathrm{P}$ via reactions of amorphous red phosphorus with a variety of copper sources. J Solid State Chem 178:970-975

Fjellvag H, Kjekshus A, Andresen AF (1984) Magnetic and structural properties of transition metal substituted MnP. III. $\mathrm{Mn}_{1-\mathrm{t}} \mathrm{Fe}_{\mathrm{t}} \mathrm{P}$ $(0.00 \leq t \leq 0.30)$. Acta Chem Scand A 38:709-718

Gingerich KA (1964) Vaporization behavior and phosphorus decomposition pressures of tungsten monophosphide. J Phys Chem 68(4):768-772

Gopalakrishnan J, Pandey S, Rangan KK (1997) Convenient route for the synthesis of transition-metal pnictides by direct reduction of phosphate, arsenate, and antimonate precursors. Chem Mater 9(10):2113-2116

Huang X, Liu Z, Dai J, Zhu Z (2010) A hydrothermal method for the synthesis of phosphides. CN Patent 101659403B

Huang H, Huang X, Zhu Z, Dai J (2011) Hydrothermal synthesis of cobalt phosphide nanoparticles. Ceram Int. doi:10.1016/ j.ceramint.2011.09.001

Li W, Dhandapani B, Oyama ST (1998) Molybdenum phosphide: a novel catalyst for hydrodenitrogenation. Chem Lett 28(3):207

Liu Z, Huang X, Zhu Z, Dai J (2010) A simple mild hydrothermal route for the synthesis of nickel phosphide powders. Ceram Int 36:1155-1158

Muettcrties EL, Sauer JC (1974) Catalytic properties of metal phosphide. Qualitative assay of catalytic properties. I. J Am Chem Soc 96(11):3410-3415

Oyama ST (2003) Novel catalysts for advanced hydro processing: transition metal phosphides. J Catal 216:343-352

Patterson AL (1939) The Scherrer formula for X-ray particle size determination. Phys Rev 56(10):978

Rowley AT, Parkin IP (1993) Convenient synthesis of lanthanide and mixed lanthanide phosphides by solid-state routes involving sodium phosphide. J Mater Chem 3(7):689-692

Rundqvist S (1966) New metal-rich phosphides of niobium, tantalum, and tungsten. Nature 211(50-51):847-848

Wang X, Wan F, Gao Y, Liu J, Jiang K (2008) Synthesis of highquality $\mathrm{Ni}_{2} \mathrm{P}$ hollow sphere via a template-free surfactantassisted solvothermal route. J Cryst Growth 310:2569-2573 